\title{
ПРОБЛЕМЫ, ОБУСЛАВЛИВАЮЩИЕ НЕВОЗМОЖНОСТЬ РЕАЛИЗАЦИИ ЭФФЕКТИВНОГО КОНТРОЛЯ ЗА РАСХОДОВАНИЕМ, БЮДЖЕТНЫХ СРЕДСТВ, НАПРАВЛЕННЫХ НА ОСУЩЕСТВЛЕНИЕ ФЕДЕРАЛЬНЫХ ПРОЕКТОВ
}

\author{
(c) 2021 Петров А. М.
}

доктор экономических наук, профессор Департамента бизнес-аналитики

Финансовый университет при Правительстве Российской Федерации, Россия, Москва

E-mail:palmi@inbox.ru

В настоящее время перед государством встает широкий спектр задач в части обеспечения достойного уровня жизни населения и улучшения благосостояния. Для достижения обозначенных задач государство реализует федеральные проекты, которые финансируются из бюджетных средств. Успешная реализация проектов возможна при внедрении и взаимодействии с эффективной системой контроля в целом и внутрифинансового контроля в частности.

Ключевые слова: индикаторы, отрасль, оценка, предприниматель, риски, рынки, ситуация, стратегия, угрозы, управление, экономические субъекты.

В условиях постоянно развивающегося мирового пространства и экономических отношений остро встает вопрос о рациональном распределении и использовании ограниченных финансовых и материальных средств. «Наряду с эффективным использованием целевых средств не менее важным аспектом является правильное распределение и работа всех ведомственных и подведомственных государственных структур, осваивающих бюджет с целью создания новых благ для общества и государства» [6].

Внутренний контроль как особая функция управления субъекта хозяйствования должен быть реализован на всех уровнях финансового управления. В свою очередь, система внутреннего финансового контроля в совокупности с законодательной базой в сфере бюджетных средств кроме фиксирования правонарушений и отклонений от плана расходования должна быть ориентирована на обоснование выводов о природе нарушений, направлений более рационального использования и предупреждения нецелевого назначения средств.

Регламент деятельности, управление субъектом хозяйствования, деятельность структурных подразделений и работу должностных лиц необходимо контролировать посредством общего внутреннего финансового контроля. Внутренний финансовый контроль по праву является важным инструментарием оценки правомерности деятельности не только на микроуровне, т.е. уровне субъектов хозяйствования и их рисков, а также инструментом оценки эффективности ре- ализации государственных проектов.

Дифференциация расходов государственного бюджета на Государственные программы и национальные проекты обуславливает целевые индикаторы документов схожих Государственных программ и национальных проектов. Так, например, во многом совпадают данные для аналитики в части показателей Государственной программы «Развитие здравоохранения» и национальном проекте «Здравоохранение», а именно: смертность населения от всех причин; младенческая смертность; смертность от болезней системы кровообращения; смертность от дорожно-транспортных происшествий; смертность от новообразований (в том числе, злокачественных). Отличительной особенностью обозначенных проектов является несоответствие их сроков завершения (как правило, Государственные программы реализуются до 2020 года, а национальные проекты до 2024 года). Однако средства, выделяемые на исполнение Государственных программ, входят в состав национальных проектов. Такой парадокс усложняет бюджетный процесс, увеличивая при этом документооборот и удорожание бюджетного контроля. С другой стороны, трудности реализации контроля за исполнением национальных проектов и формирования индикаторов могут вызвать непрозрачные и двусмысленные формулировки мероприятий, реализуемых в рамках национальных программ.

Выделим две ключевые причины, обуславливающие невозможность реализации эффек- 
тивного контроля за расходованием, бюджетных средств, направленных на осуществление федеральных проектов [6]:

А) Проблема «регионов».

Б) Отсутствие системы наблюдаемых показателей.

В Российской Федерации составлен достаточно существенный список проблем в части функционирования общей законодательной модели и подходов к осуществлению финансового контроля, включающего в себя как внутренний, так и внешний финансовый контроль муниципальных и федеральных уровней.

В общей классификации финансовый контроль принято разделять на: государственный (общегосударственный и ведомственный); внутрихозяйственный (корпоративный, внутрифирменный); независимый (аудиторский) [7].

Первостепенной целью для государственного контроля является соблюдение законности через создание и полное соблюдение четкой нормативной базы, регламентирующей работу и осуществление финансового контроля. Предметом государственного контроля выступят: нормативные акты, регламентирующие контрольную деятельность, ее подготовку и осуществление; прикладные программы, выступающие в качестве автоматизированных контрольных единиц; ведомственный перечень нарушений, отражающий качество выполнения государственных функций.

Проведение системного государственного финансового контроля является одними из преимущественных задач современной бюджетной политики Российской Федерации, в которой контрольные мероприятия должны соответствовать международным и европейским стандартам финансового контроля.

На сегодняшний день в России принят федеральный закон «О внесении изменений в Бюджетный кодекс Российской Федерации в части совершенствования государственного (муниципального) финансового контроля, внутреннего финансового контроля и внутреннего финансового аудита». Федеральный закон разработан и принят для сближения контрольных внутренних мероприятий в нашей стране и их сближением со стандартами МОВОФК [6]. Законом уточняется понятийный аппарат в части внутреннего финансового контроля и аудита, что необходимо для более детального и четкого понимания вопросов их изучения и эффективности [1].
Основным документом в вопросе регулирования бюджетных средств является Бюджетный кодекс РФ (далее БК) [6]. Бюджетный контроль, в свою очередь, является непосредственным компонентом государственного финансового контроля, направленным на соблюдение законности, достоверности и эффективности расходования бюджетных средств, а также работы участников регулирования.

Внутренний финансовый контроль, являясь универсальной функцией управления, способствует получению данных вариативности влияния различных факторов на изменение уровня эффективности реализации проектов (мероприятий). Инструментарий внутреннего финансового контроля многообразен и многогранен, что в свою очередь способствует подбору эффективной концепции его исполнения.

В современных условиях самым эффективным и широко используемым инструментом внутреннего финансового контроля является риск-ориентированный подход, основанный на анализе качественных и количественных факторов, обеспечивающий детальный подход к анализу, позволяющий вскрывать ошибки и недочеты в работе субъекта хозяйствования.

«Внутренний финансовый контроль государственных и муниципальных субъектов можно разделить на основные направления: внутренний финансовый контроль, внутренний аудит, управление рисками» [5].

«Важно отметить факт того, что в современных экономических реалиях внутреннего финансового контроля должен быть включен и детально рассмотрен антикоррупционный аспект, анализ которого увеличит эффективность расходования средств и повысит общую исполнительность должностных и ответственных лиц» [6].

Эффективная система внутреннего финансового контроля, обладающая возможностями в части работы, нацеленной на опережающее устранение предпосылок финансовых нарушений по расходованию средств на федеральные проекты, опирается на данные анализа действующих методов внутреннего финансового контроля. В ходе исследования действующих методик внутреннего финансового контроля, а также эффективности системы внутреннего финансового контроля изучены лучшие российские и зарубежные практики и разнообразный инструментарий.

В рамках проеденного исследования отме- 
тим, что зачастую понятие «внутренний финансовый контроль» отождествляется с понятием «внутренний аудит». Однако, до настоящего времени, под внутренним аудитом понимался процесс, подчиненный внутреннему контролю. Так английский специалист Додж Р. трактовал понятие внутренний аудит, как «составную часть внутреннего контроля, осуществляемого по решению органов управления компанией для целей контроля и анализа хозяйственной деятельности» [4]. Нельзя не согласиться с мнением Р. Додж в том, что «внутренний аудит» является составной частью «внутреннего финансового контроля».

Так, М. В. Мельник считает, что «внутренний контроль - одна из основных функций управления, представляющая собой систему постоянного мониторинга и проверки хозяйственной деятельности субъектов хозяйствования, необходимая для оценки правильности и эффективности принятых управленческих решений, выявления отклонений и своевременного их устранения, снижения рисков деятельности и управлению обусловленными рисками» [2].

«Внутренний аудит выявляет как слабые места в системе финансового управления и контроля, так и потенциальные возможности для повышения эффективности деятельности орга- низации» [8]. Рассматриваемый как контролирующий процесс, который имеет цели, объем, функции и задачи, внутренний аудит является фактическим, реальным фактором, влияющим на достижение стратегического и оперативного плана организаций государственного сектора. Существенная проблема практического применения состоит не в том, чтобы прояснить важность внутреннего аудита, а в том, чтобы определить, достиг ли он своей цели в части повышения эффективности работы субъекта хозяйствования посредством охвата всех затрат на федеральные проекты.

Таким образом, следует отметить, что внутренний финансовый контроль - это постоянный процесс, реализуемый должностными лицами субъекта хозяйствования, выполняющих процедуры составления и исполнения бюджета, ведущих бюджетный учет и формирующих бюджетную отчетность. В свою очередь, можно выделить три основных направления внутреннего финансового контроля: соблюдение бюджетных правоотношений, процедур составления и исполнения бюджета; соблюдение процедур составления отчетности и ведения бюджетного учета; подготовка и реализация мер по повышению экономности и эффективности использования бюджетных средств [3].

\section{Библиографический список}

1. Федеральный закон от 26.07.2019 № 199-ФЗ «О внесении изменений в Бюджетный кодекс Российской Федерации в части совершенствования государственного (муниципального) финансового контроля, внутреннего финансового контроля и внутреннего финансового аудита» // СПС КонсультантПлюс.

2. Батуева, А. Б. Система внутреннего контроля / А. Б. Батуева // Молодой ученый. - 2018. - № 16 (202). - С. $148-150$.

3. Завьялова, Л.В., Шилехин, К.Е. Внутренний финансовый контроль в условиях нового законодательства // Вестник Омского университета. Серия «Экономика».-2013. - № 4.- С. 88-99.

4. Кучеров, А.В. Внутренний аудит в России / А.В. Кучеров, Е.В. Леушина.- Текст: непосредственный, электронный // Молодой ученый. - 2013. - № 6 (53). - C. 359-362._ URL: https://moluch.ru/archive/53/7029/.

5. Петров А. М., Бурцева К. Ю. К вопросу организации внутреннего финансового контроля в рамках расходования средств на федеральные проекты // Экономические науки. - 2020. - № 188. - С. 113-119.

6. Петров, A.M. Оперативный и превентивный инструментарий реализации внутреннего финансового контроля в рамках расходования средств на федеральные проекты // Экономические науки. - 2020._ № 185.С. 169-178.

7. Саввина, О.В. О современной модели финансового надзора // Финансы и кредит. - 2015.- № 34 (658).- С. 47-57.

8. Nedyalkova P. Quality of Internal Auditing in the Public Sector Perspectives from the Bulgarian and International Context Univ. of Econ. - Varna, 2019, pp. 266.

9. Chernysheva N.A., Perskaya V. V., PetrovA.M., Bakulina A.A. GREEN ENERGY FOR BELT AND ROAD INITIATIVE: ECONOMIC ASPECTS TODAY AND IN THE FUTURE / International Journal of Energy Economics and Policy. 2019. T. 9. № 5. C. 178-185.

10. Kevorkova Z.A., Petrov A. M., Savina N. V. TOWARDS LIABILITIES OF CORPORATE SYSTEMS / International Journal of Civil Engineering and Technology. 2019. T. 10. № 2. C. 1582-1593. 
11. Petrov A.M., NikiforovaE.V., Kiseleva N.P., Grishkina S.N., LihtarovaO.V. CREATION OF THE REPORTING ON SUSTAINABLE DEVELOPMENT OF COMPANIES BASED ON SOCIOECONOMIC MEASUREMENT STATISTICS / International Journal of Recent Technology and Engineering. 2019. T. 8. № 2. C. 4005-4012.

12. SotnikovaL.V., Polenova S.N., Mislavskaya N.A., PetrovA.M., BasovaM.M. SUSTAINABlE DeVelopment, MACRO AND MICRO LEVEL: RUSSIAN AND FOREIGN MODEL / International Journal of Recent Technology and Engineering. 2019. T. 8. № 2. C. 4524-4532.

13. Kosolapova M.V., Muravitskaya N.K., Tolmachev M. N., Melnikova L.A., PetrovA.M. TECHNOLOGY FOR SOLVING THE PROBLEMS RELATED TO THE IMPLEMENTATION OF THE CONCEPT OF PRESERVING CAPITAL IN ACCOUNTING AND STATISTICS / International Journal of Recent Technology and Engineering. 2019. T. 8. № 3. C. 789-792.

14. Kosolapova M.V., PetrovA.M., YshanovI.G., MuravitskayaN.K., NurmuhamedovaH.S. THE ECONOMIC SIGNIFICANCE OF STATISTICAL RESEARCH ACTIVITIES OF REPRESENTATIVE OFFICES OF COMPANIES ABROAD / International Journal of Innovative Technology and Exploring Engineering. 2019. T. 8. № 10. C. $2713-$ 2722.

15. Petrov A.M., Yurasova I. O., Putihin Y.E., Poluleh M. V., Erohina V.N. ACCOUNTANT MODELING TECHNOLOGY AND STATISTICS IN THE CONTEXT OF THE NEW EDUCATIONAL CONCEPT / International Journal of Innovative Technology and Exploring Engineering. 2019. T. 8. № 12. C. 3214-3217.

16. Petrov A.M., Kiseleva N.P., Kevorkova Z.A., Melnikova L.A., YshanovI.G. PRESENT DEVELOPMENT PRACTICES FOR TAX, FINANCIAL AND STATISTICAL REPORTING IN THE RUSSIAN FEDERATION / International Journal of Innovative Technology and Exploring Engineering. 2019. T. 8. № 12. C. 3538-3542.

17. Karpova T.P., Petrov A.M., Antonova O.V. DIRECTIONS OF ACCOUNTING DEVELOPMENT IN THE CONDITIONS OF DIGITALIZATION / Journal of Advanced Research in Dynamical and Control Systems. 2018. T. 10. № 7 Special Issue. C. $117-125$.

18. Lymar M.P., Kevorkova Z.A., Petrov A. M. THE CONVERGENCE OF NATIONAL AND INTERNATIONAL ACCOUNTING STANDARDS: CHINESE EXPERIENCE / International Journal of Civil Engineering and Technology. 2018. T. 9. № 13. C. 82-94. 